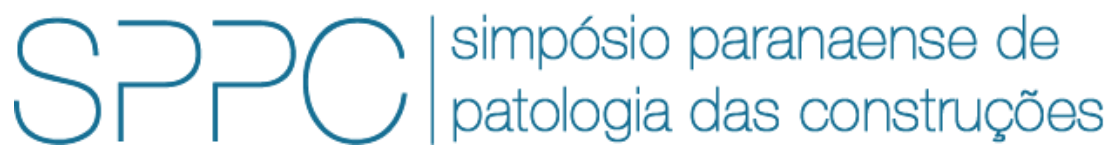

ISSN 2526-7248 artigo 2SPPC2005, pp. 512-522, 2017

\title{
Estudo da influência do teor de umidade na verificação do índice de penetração estático e dinâmico
}

\author{
João Henrique de Freitas ${ }^{1}$, Jeselay Hemetério dos Reis ${ }^{2}$ e Antonio Belincanta ${ }^{3}$ \\ 1 Universidade Estadual de Maringá, joaohenriquedefreitas@gmail.com \\ 2Doutor, Universidade Estadual de Maringá, jeselay@hotmail.com \\ 32Doutor, Universidade Estadual de Maringá, abelincanta@uem.br
}

\begin{abstract}
Resumo: No campo da investigação geotécnica o Penetrômetro de Cone Dinâmico (DCP) e o Penetrométrico de Cone Estático (ECP) vêm se firmando como um método alternativo para avaliar a capacidade de suporte do solo em camada de subleito de rodovias e de aterros. Por meio do índice de penetração $(S)$ do DCP ou da tensão de ruptura $\left(q_{c}\right)$ do ECP é possível verificar a resistência do solo. Esses ensaios destacam-se pela agilidade e simplicidade de operação. O efetivo controle de compactação de solo, pelo método tradicional, tem sido considerado dispendioso, em termos de tempo e recursos. No entanto o controle de compactação de solo na pavimentação é imperativo para o bom desempenho da obra, evitando-se com isto as indesejáveis patologias. Nesse contexto este trabalho trata da utilização do DCP e ECP para o controle da resistência das camadas de solo compactados, por meio do índice de penetração e do teor de umidade do solo, oferecendo a possibilidade de se realizar um grande número de ensaios no decorrer da obra, com redução no tempo e nos custos no processo de coleta de dados. Este trabalho também objetiva avaliar a relação entre os resultados do DCP e ECP para diferentes teores de umidade de um solo compactado. Para tanto utilizou-se dos ensaios do DCP e do ECP em amostra de solo compactados em laboratório, em diferentes condições de umidade, no qual pode-se estabelecer a relação do índice de penetração (S) ou da tensão de ruptura $\left(\mathrm{q}_{c}\right)$ com os índices físicos: teor de umidade e peso especifico aparente seco. Os resultados encontrados colaboram com aplicabilidade dos ensaios penetrométricos no controle de compactação de solo.
\end{abstract}

Palavras-chave: Cone penetrométrico dinâmico. Cone penetrométrico estático. Controle de compactação de solo.

Abstract: In the field of geotechnical investigation the Dynamic Cone Penetration (DCP) and the Static cone Penetration (ECP) have been established as an alternative method to evaluate the support capacity of the soil in the subsurface layer of highways and landfills. By means of the penetration index (S) of the DCP or the rupture stress (qc) of the ECP it is possible to verify the soil resistance. These tests stand out for the agility and simplicity of operation. Effective control of soil compaction by the traditional method has been considered costly in terms of time and resources. However, the soil compaction control in the paving is imperative for the good performance of the work, avoiding with this the undesirable pathologies. In this context, this work deals with the use of the DCP and ECP to control the resistance of the layers of compacted soil, through the penetration index and soil moisture content, offering the possibility of carrying out a large number of tests in the course of the work, with reduction in the time and costs spent in the process of data collection. This work also aims to evaluate the relationship between the results of the PDD and ECP for different moisture contents of a compacted soil. In order to do so, we used the DCP and ECP tests in a laboratory-compacted soil sample under different humidity conditions, in which the ratio of penetration index (S) or rupture stress (qc) can be established with The physical indexes: moisture content and specific apparent dry weight. The results found contribute to the applicability of the penetrometric tests in soil compaction control.

Key words: Dynamic penetrometer cone. Static penetrometer cone. Soil compaction control. 
FREITAS, J. H.; REIS, J. H.; BELINCANTA, A., ESTUDO DA INFLUÊNCIA DO TEOR DE UMIDADE NA VERIFICAÇÃO DO ÍNDICE DE PENETRAÇÃO ESTÁTICO E DINÂMICO. $2^{\circ}$ Simpósio Paranaense de Patologia das Construções (20 SPPC), artigo 2SPPC2005, pp. 512-522, 2017. DOI: 10.4322/2SPPC.2017.042

\section{Introdução}

Toda obra de engenharia está relacionada com o solo por ela envolvido. 0 conhecimento sobre o solo é de fundamental importância para uma previsão adequada do comportamento do mesmo. Por esse motivo a caracterização física e mecânica é essencial para uma melhor análise das transmissões de esforços pelo solo. Entretanto os métodos de coleta de amostras mostram-se algumas vezes inviáveis devido a necessidade de pessoas capacitadas, laboratórios próximo à obra e equipamentos de fácil transporte. Tais fatores implicam em custo e tempo, fazendo com que algumas obras sejam executadas sem o monitoramento adequado [1].

As obras, executadas sem o controle de qualidade ou que não prezam pela verificação continua das etapas executadas, são obras com grande potencial ao surgimento de patologia. Em obras rodoviárias destaca-se a necessidade de camadas de solo compactado, que ofereçam condições adequadas de suporte. A compactação é uma das técnicas mais antigas, utilizada para o melhoramento do solo em obras geotécnicas. De maneira geral, esta técnica possibilita o aumento da resistência ao cisalhamento e as reduções da deformabilidade e da permeabilidade, [2].

Em busca de opções para se fazer o controle de compactação de camada de pavimento e de aterro, deu-se início a utilização dos chamados penetrômetros, que podem ser de dois tipos: estático e dinâmico. Estes equipamentos possuem a característica de determinar indiretamente a resistência da camada de solo penetrada.

O DCP (Penetrômetro de Cone Dinâmico) é constituído de uma ponteira cônica, cravada no solo através do impacto de um martelo em queda livre, com energia padronizada. É um dispositivo leve, que pode ser convenientemente utilizado para a investigação de aterro compactado ou não, inclusive em locais de difícil acesso. Os resultados do DCP podem ser utilizados rapidamente para avaliar a variabilidade das condições do solo, permitindo inclusive a identificação de diferentes camadas.

O penetrômetro de cone estático (ECP) também é constituído por uma ponteira cônica, que é cravada no solo, por meio de uma carga estática aplicada na parte superior da composição de hastes, de forma mecânica ou manual, medindo ao longo da profundidade a tensão de ruptura.

A investigação por meio do penetrômetro de cone estático (ECP) se caracteriza pela determinação da tensão de ruptura $\left(q_{c}\right)$, valor que corresponde à tensão necessária para a penetração da ponteira cônica na superfície analisada. Para o penetrômetro de cone dinâmico (DCP), o valor investigado é o índice de penetração (S), que corresponde a penetração por golpe do martelo.

Segundo [1] os parâmetros de índice de penetração $(S)$ e de tensão de ruptura $\left(\mathbf{q}_{c}\right)$, apesar de sua dependência com o peso específico aparente seco do solo, são fortemente afetados pelo teor de umidade presente no solo. Assim sendo, este trabalho apresenta uma análise da variação do índice de penetração (S) e da tensão de ruptura $\left(q_{c}\right)$ com os índices físicos do solo: teor de umidade $(w)$ e peso especifico aparente seco $\left(\gamma_{d}\right)$. O trabalho busca inclusive validar a aplicabilidade dos ensaio penetrométricos na verificação da umidade presente em camadas de solo compactadas. 
FREITAS, J. H.; REIS, J. H.; BELINCANTA, A., ESTUDO DA INFLUÊNCIA DO TEOR DE UMIDADE NA VERIFICAÇÃO DO ÍNDICE DE PENETRAÇÃO ESTÁTICO E DINÂMICO. $2^{\circ}$ Simpósio Paranaense de Patologia das Construções (2० SPPC), artigo 2SPPC2005, pp. 512-522, 2017. DOI: 10.4322/2SPPC.2017.042

\section{Características dos penetrômetros estático e dinâmico, utilizados}

Os Penetrômetros são instrumentos que permitem realizar ensaios de penetração no solo em seu estado natural ou compactado, com objetivo da avaliação da resistência. [3]

O Penetrômetro de cone estático utilizado na Universidade Estadual de Maringá é constituído de uma haste de penetração com $50 \mathrm{~cm}$ de comprimento e 15,8 mm de diâmetro, tendo em sua extremidade uma ponteira cônica de $20 \mathrm{~mm}$ de diâmetro e ângulo de ataque de $60^{\circ}$, e por fim também de um sistema de aplicação e de medição de carga. O penetrômetro de cone estático é cravado pela aplicação manual ou mecânica de carga estática, sendo esta carga geralmente medida por meio de anel dinamométrico.

O Penetrômetro de cone dinâmico utilizado na Universidade Estadual de Maringá é constituído de um conjunto de hastes metálicas de aço de 15,8 mm, de cravação e de guia, uma cabeça de bater e um martelo. O conjunto de hastes de cravação de $15,8 \mathrm{~mm}$ de diâmetro possui em sua extremidade uma ponteira cônica de aço com 20 $\mathrm{mm}$ de diâmetro e ângulo de ataque de $60^{\circ}$. O conjunto penetra no solo sob ação da queda livre de uma martelo de $80 \mathrm{~N}$, de $50 \mathrm{~mm}$ de diâmetro, direcionado por uma haste guia de 15,8 mm de diâmetro, operado com altura de queda de $553 \mathrm{~mm}$.

A partir dos dados obtidos em campo traça-se a curva do DCP, sendo nas ordenadas as profundidades de cravação em $(\mathrm{cm})$ e nas abscissas o número de golpes para alcançar a profundidade de cravação. Neste caso a inclinação da curva se relacionaria com o índice de penetração (S) em cm/golpe.

Por meio da curva do DCP, pode-se verificar a homogeneidade de compactação no decorrer da profundidade da camada analisada, ou seja, pode verificar o grau de compactação no decorrer da profundidade na camada ou a distinção das camadas de solo [4].

Quanto às vantagens dos penetrômetros de cone dinâmico e estático, observa-se que são ferramentas extremamente versáteis, simples na conceituação e na operação. São relativamente rápidos na obtenção de resultados e efetivamente econômicos, quando comparados aos demais ensaios convencionalmente usados [5]. Não é necessária uma frequência constante de aplicação de golpes ou de força. A execução do ensaio é relativamente simples [1]. É um equipamento portátil, de fácil manuseio e transporte.

Pode-se destacar como desvantagem da utilização dos penetrômetros de cone dinâmico e estático: a elevada variação dos resultados no caso de materiais granulares. O uso do DCP para materiais granulares grosseiros é contestável e questionável [6]. A correlação entre índice de penetração e a tensão de ruptura é empírica. O DCP não é um ensaio que fornece as propriedades diretamente, e sim um ensaio que fornece índices a serem relacionados com os parâmetros do solo através de correlações [1]. 


\section{Relação do índice de penetração (S) com o teor de umidade e peso específico aparente $\operatorname{seco}\left(\gamma_{\mathrm{d}}\right)$}

Em experimentos realizados anteriormente com solo compactado pode-se observar que há uma relação biunívoca do índice de penetração com o teor de umidade e peso especifico aparente seco do solo ou grau de compactação, sendo do tipo das equações 1 e 2, [7]:

$$
\begin{array}{r}
S=c_{1} \frac{\gamma_{d \max }}{\gamma_{d}} e^{c_{2}\left(\frac{w-w_{o t}}{w_{o t}}\right)} \\
G C=\frac{c_{1}}{S} e^{c_{2}\left(\frac{w-w_{o t}}{w_{o t}}\right)}
\end{array}
$$

Onde o S é o índice de penetração em (cm/golpe); Yd é o peso especifico aparente seco do solo; w é o teor de umidade presente no solo; Wot. e $\gamma$ dmax. são respectivamente o teor de umidade ótima e peso específico aparente seco máximo, obtidos em ensaios de compactação de laboratório, c $c_{1}$ e $c_{2}$ são as constantes de ajustes e GC grau de compactação em porcentagem.

Pode-se observar pela equação acima que o índice de penetração (S) depende fortemente dos índices físicos do solo. Na equação 1 observa-se que o índice de penetração é inversamente proporcional ao peso especifico aparente seco do solo $(\gamma d)$, porém, no que se refere ao teor de umidade, verifica-se que a relação é do tipo exponencial, sendo esta última observação ilustrada na figura 1, proveniente de dados obtidos com solo compactado em laboratório e no campo [8]. 


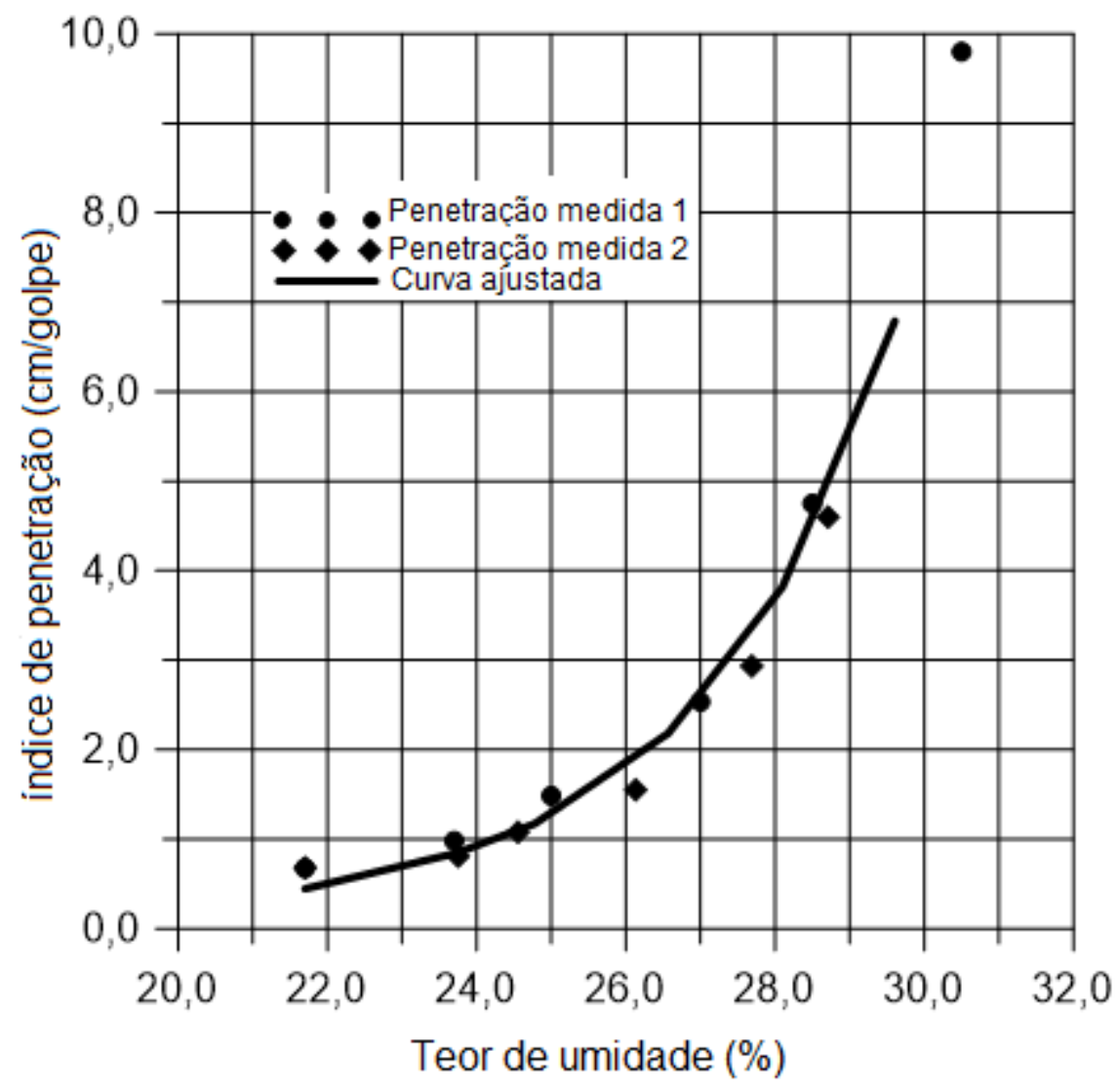

Figura 1: Relação do índice de penetração em função do teor de umidade. [8]

Segundo [8], o uso do DCP no controle da compactação no campo é de um grande potencial. Desta forma, o controle pode ser realizado in situ medindo-se o índice de penetração (S) e o teor de umidade do solo compactado. Uma vez que eles estão diretamente relacionados com o grau de compactação da camada.

\section{Materiais e método}

O solo estudado foi coletado na cidade de Mandaguaçu, localizada na Região Noroeste do Estado do Paraná. A amostra coletada para a realização dos experimentos em laboratório foi retirada de uma camada superficial de solo evoluído. A quantidade de material coletado foi estimada, considerando os ensaios de compactação e ensaios de penetração de cone estático e dinâmico. Após a coleta do solo, realizou-se a preparação do mesmo por meio do destorroamento e peneiramento na peneira de malha de $2 \mathrm{~mm}$ (peneira $\mathrm{n}^{\circ} 10$ ). Após a homogeneização do solo, o mesmo foi acondicionado em barris de plástico, devidamente identificado e estocado no Laboratório de solos do Departamento de Engenharia Civil (DEC).

\subsection{Solo estudado}

O solo estudado provém da camada superficial de solo evoluído, originário do Arenito Caiuá. Apresenta-se com a textura de areno-argilosa e está englobado na classe do Latossolo Vermelho distrófico (antigo Latossolo Vermelho-escuro). 


\subsection{Ensaios realizados e procedimentos}

Com o solo coletado foram realizados em laboratório ensaios visando a caracterização e a compactação, utilizando para isto as normas vigentes da Associação Brasileira de Normas Técnicas (ABNT), entre elas as NBR 6457(1986), NBR 6508(1984), NBR 7181(1984) e NBR 7182(1984), respectivamente indicadas nas referências $9,10,11$ e 12 .

No ensaio de compactação os corpos de prova foram moldados na energia normal $\left(600 \mathrm{kN} . \mathrm{m} / \mathrm{m}^{3}\right)$, com o uso do cilindro e soquete pequenos.

Os corpos de prova compactados para os ensaios penetrométricos foram moldados no cilindro grande de compactação, sem espaçador, disponibilizando desta maneira uma maior profundidade de penetração, mantendo-se a energia normal de compactação.

Para um melhor estudo do comportamento do solo frente ao índice de penetração (S), foram moldados três séries de quatro corpos de prova, compactados nos teores de umidade relacionados à ótima ( $\left.w_{o t}\right)$ : sendo dois acima e dois abaixo da umidade ótima, totalizando 12 corpos de prova.

Para os ensaios com penetrômetro de cone estático, foram moldados duas series de cinco corpo de prova de prova, compactados nos teores de umidade relacionados à ótima (wot), sendo dois acima e três abaixo da umidade ótima, totalizando dez corpos de prova.

\section{Resultados e análise}

Os resultados obtidos nesse trabalho são apresentados na forma de tabelas e gráficos, com a devida análise.

\subsection{Resultados dos ensaios de caracterização e compactação.}

Existem diversos sistemas de classificação de solos, o método utilizado para o presente trabalho baseia-se, na análise granulométrica e na HRB/AASHTO (Highway Research Board). Pelos dados contidos na Tabela 1, este solo é do tipo areia argilosa, A-2-6.

Tabela 1

\begin{tabular}{cccccccccc}
\hline $\begin{array}{c}\text { Local da } \\
\text { retirada }\end{array}$ & Areia & Argila & Silte & $\begin{array}{c}\text { LL } \\
(\%)\end{array}$ & $\begin{array}{c}\text { LP } \\
(\%)\end{array}$ & $\begin{array}{c}\text { IP } \\
(\%)\end{array}$ & IG & HRB & $\begin{array}{c}\text { NBR } \\
6508 / 95\end{array}$ \\
\hline Mandaguaçu & 66,03 & 28,91 & 5,46 & 30 & 17 & 13 & 0,6 & $\begin{array}{c}\text { A-2-6 } \\
\text { Areia } \\
\text { argilos } \\
\text { a }\end{array}$ & $\begin{array}{c}\text { Areia } \\
\text { argilosa }\end{array}$ \\
\hline
\end{tabular}

Em termos de compactação na energia normal, conforme curva de compactação apresentada na Figura 2, obtida em ensaio específico, realizado com cilindro 
pequeno, este solo se apresenta com um teor ótimo de umidade de 12,6 \% e um peso especifico aparente seco máximo de $18,9\left(\mathrm{kN} / \mathrm{m}^{3}\right)$.

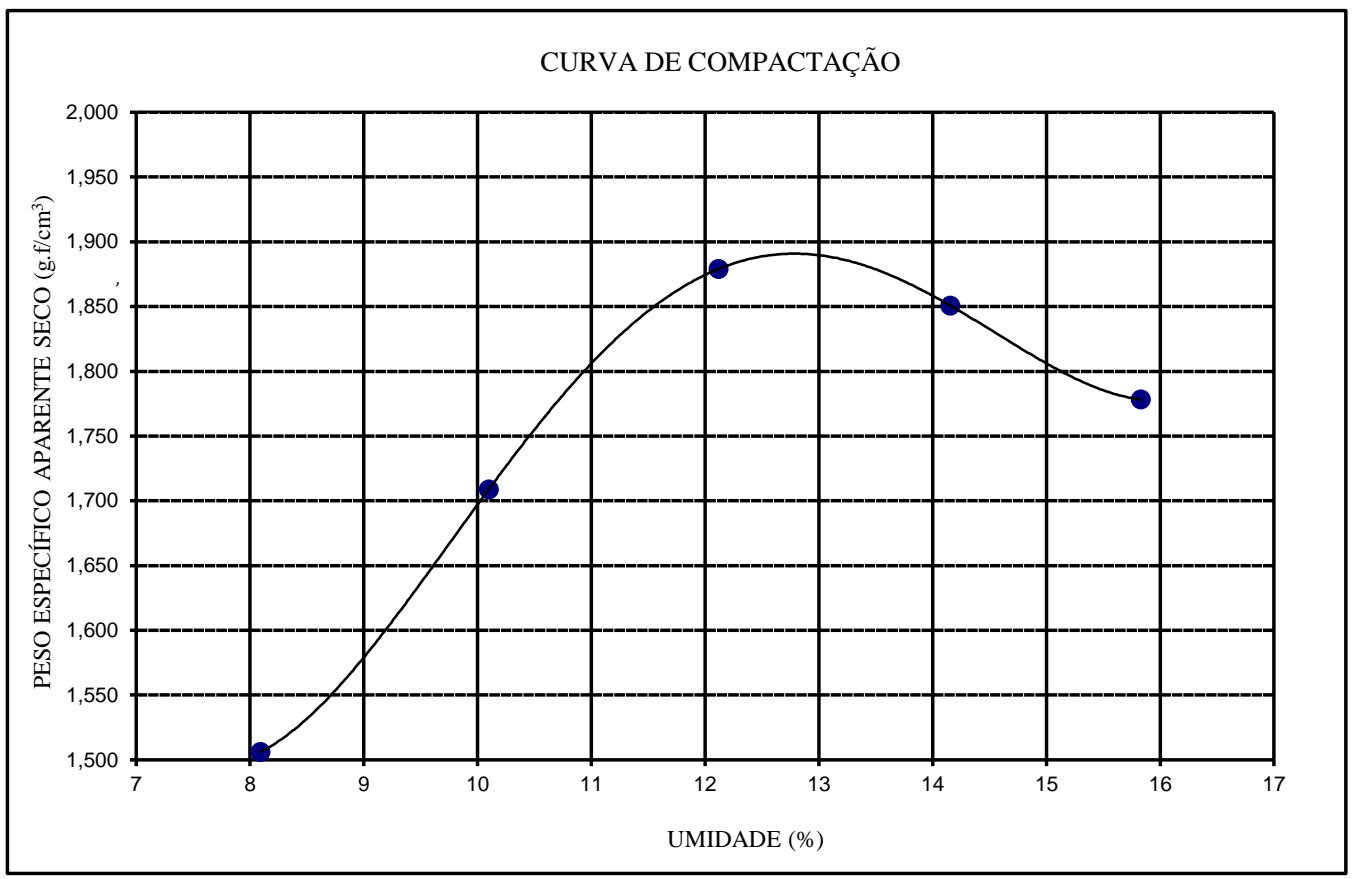

Figura 2: Curva de compactação, energia normal.

\subsection{Tensão de ruptura $\left(q_{c}\right)$ e $\left(Y_{d}\right)$ em função do teor de umidade $(w)$}

Observa-se na Figura 3 a combinação de dois gráficos independentes: obtidos pela média dos pares de tensão de ruptura $\left(q_{c}\right)$ em função do teor de umidade $(w)$ e peso específico aparente seco $\left(\mathrm{Y}_{\mathrm{d}}\right)$ em função do teor de umidade $(\mathrm{w})$, para o solo compactado na energia normal. Para cada valor de umidade, o solo se apresenta com uma tensão de ruptura distinta, sendo decrescente com o valor da umidade.

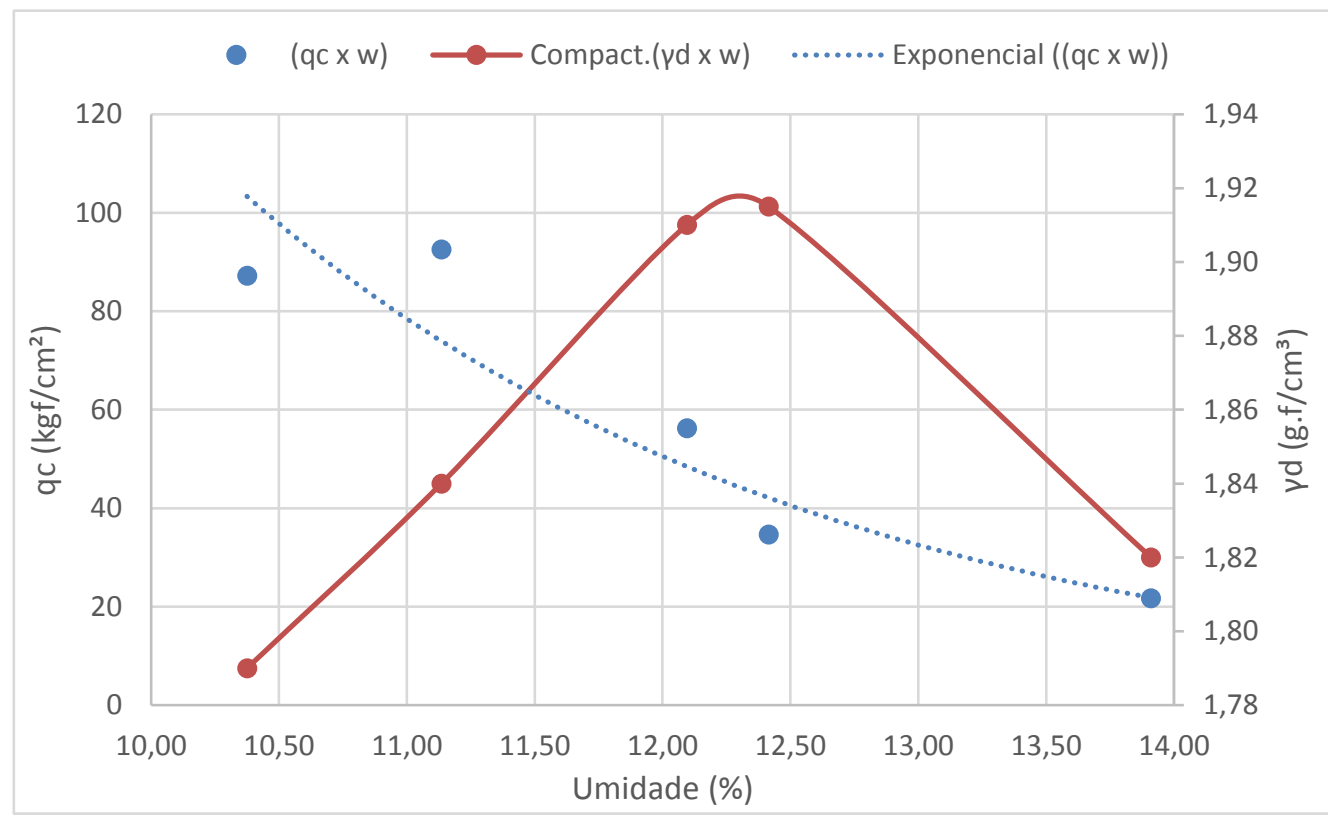

Figura 3: Curvas de tensão de ruptura $\left(q_{c}\right)$ e $\left(Y_{d}\right)$ em função da umidade de compactação (w). 


\section{3 Índice de penetração (S) e (yd) em função do teor de umidade (w)}

Observa-se na Figura 3 a combinação de dois gráficos independentes: obtidos pela média de três valores de índice de penetração $(S)$ em função do teor de umidade $(w)$ e peso específico aparente seco $\left(\mathrm{Yd}_{\mathrm{d}}\right.$ ) em função do teor de umidade $(\mathrm{w})$, para o solo compactado na energia normal. Para cada valor de umidade, o solo se apresenta com um índice de penetração distinto, sendo crescente com o valor da umidade.

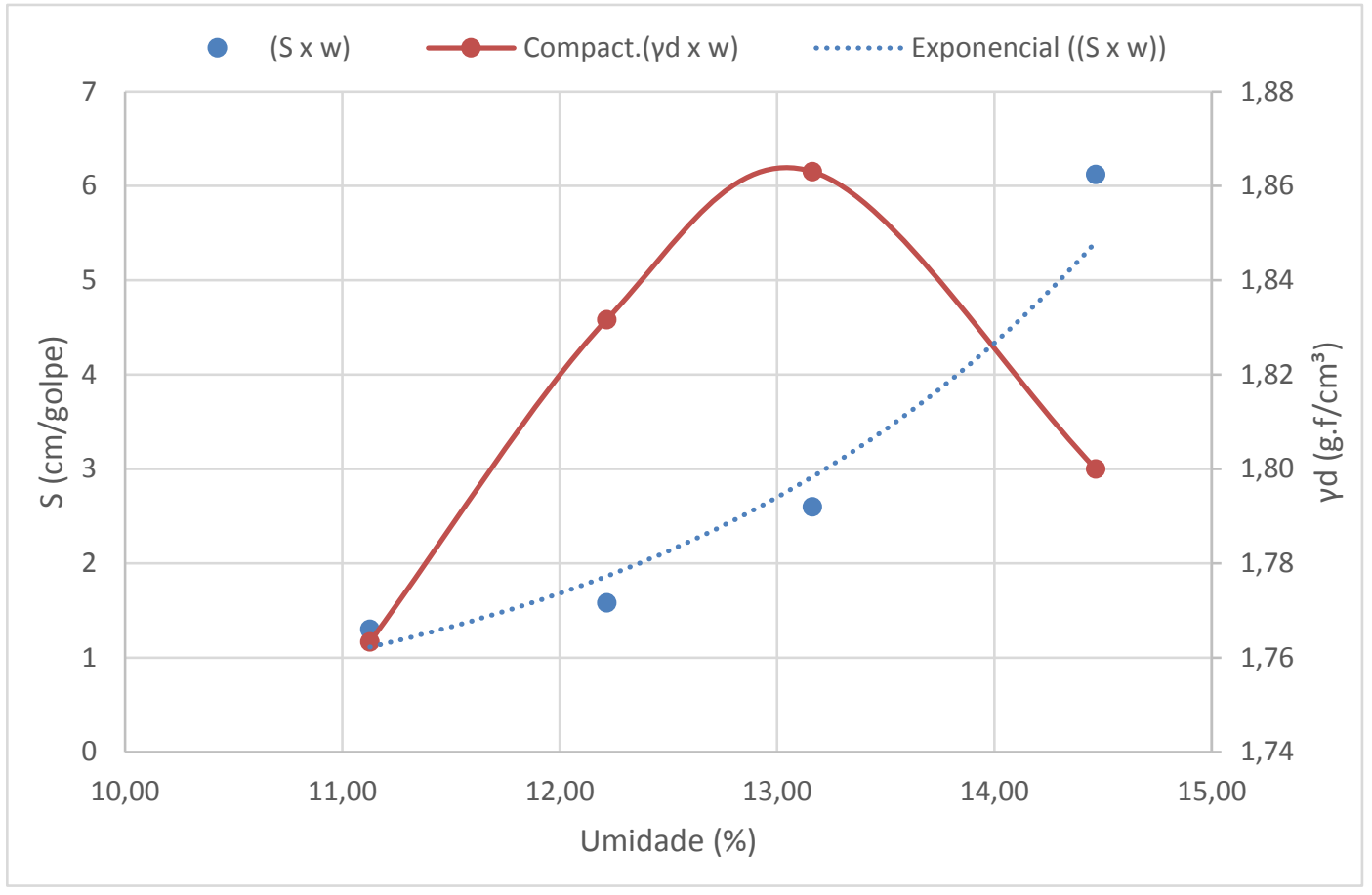

Figura 4: Curvas de índice de penetração $(S)$ e $\left(Y_{d}\right)$ em função da umidade de compactação (w).

\section{4 Índice de penetração (S) em função do teor de umidade (w)}

$\mathrm{Na}$ figura 5 apresenta-se a linha de tendência ajustada do tipo exponencial, relacionando o índice de penetração (S), em cm/golpe, com o teor de umidade (w), em porcentagem, para solo compactado na energia normal. Nota-se que o índice de penetração é crescente com o teor de umidade, de forma exponencial, colaborando com o observado por outros pesquisadores [8]. 
FREITAS, J. H.; REIS, J. H.; BELINCANTA, A., ESTUDO DA INFLUÊNCIA DO TEOR DE UMIDADE NA VERIFICAÇÃO DO ÍNDICE DE PENETRAÇÃO ESTÁTICO E DINÂMICO. $2^{\circ}$ Simpósio Paranaense de Patologia das Construções (20 SPPC), artigo 2SPPC2005, pp. 512-522, 2017. DOI: 10.4322/2SPPC.2017.042

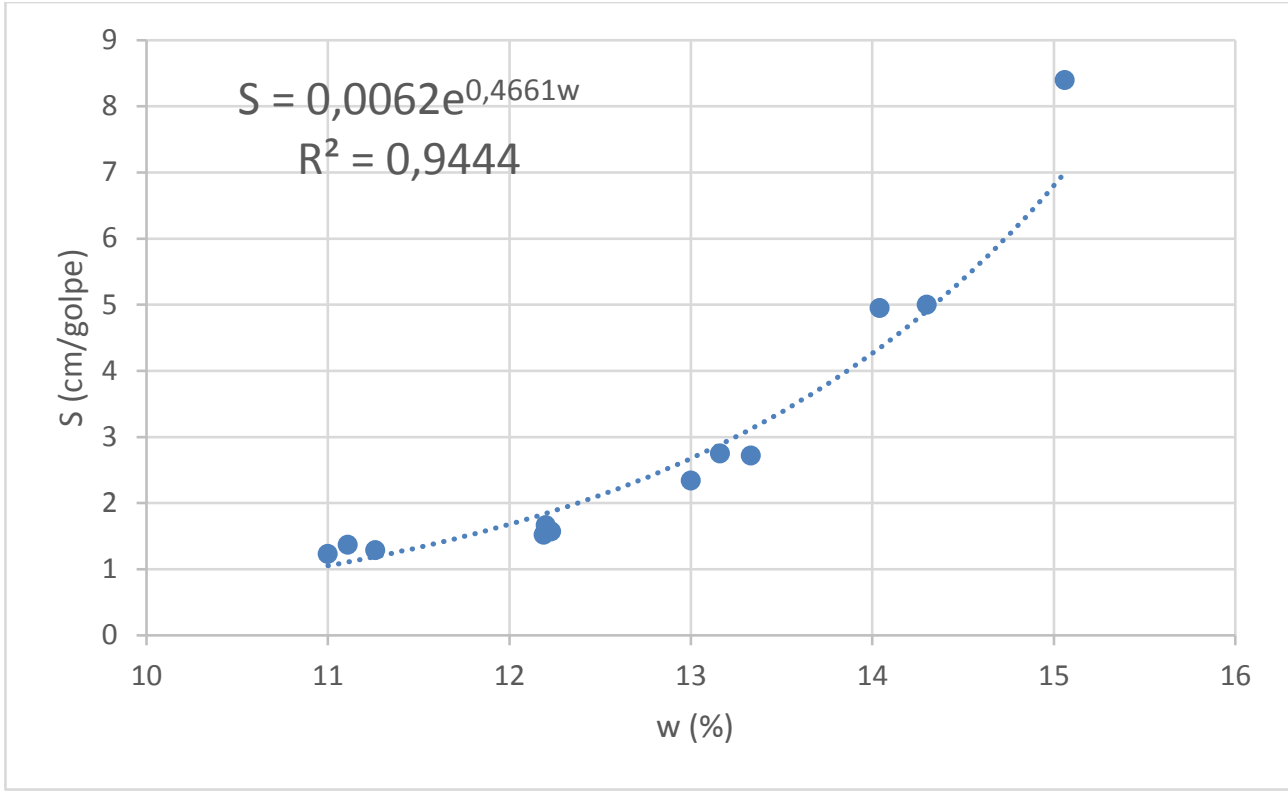

Figura 5: Índice de penetração em função do teor de umidade, para o solo compactado na energia normal.

\section{5 Índice de penetração (S) e grau de compactação (G.C) em função do teor de umidade $(w)$}

$\mathrm{Na}$ figura 6 apresenta-se a linha de tendência ajustada do tipo exponencial, relacionando o produto do índice de penetração $(\mathrm{S}$, em $\mathrm{cm} / \mathrm{golpe})$ com o grau de compactação (G.C, em porcentagem), com o teor de umidade (w, em porcentagem), para o solo compactado na energia normal, com teor ótimo de referência de 12,6 \% e peso específico aparente seco máximo de referência de $18,9 \mathrm{kN} / \mathrm{m}^{3}$.

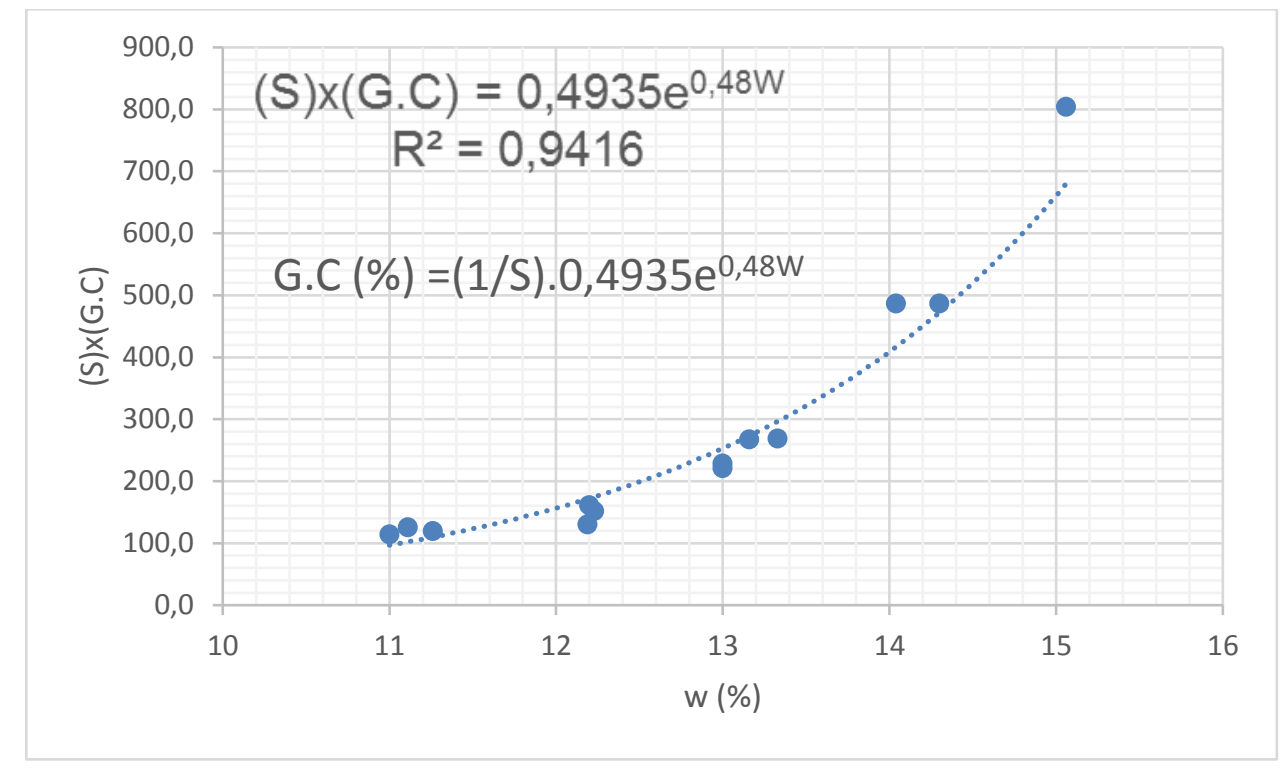

Figura 6: Produto do índice de penetração pelo grau de compactação em função do teor de umidade, para o solo compactado na energia normal. 
Por meio da linha de tendência apresentada na figura 6 pode-se obter a equação 3, que relaciona o grau de compactação (G.C), em porcentagem, com o índice de penetração (S), em cm/golpe e teor de umidade (w), em porcentagem.

$$
\text { G.C }(\%)=\frac{0,4935}{S} e^{0,48 \cdot w}
$$

\section{Conclusão}

Nesta seção serão apresentadas as principais conclusões desta pesquisa. Vale ressaltar que as conclusões apresentadas estão associadas ao tipo de solo estudado, coletado na cidade de Mandaguaçu-PR, localizada na Região Noroeste do Estado do Paraná, sendo este solo um A-2-6, areia argilosa, solo evoluído proveniente do Arenito Caiuá.

A partir das análises dos resultados pode-se verificar que o índice de penetração (S) e a tensão de ruptura $\left(q_{c}\right)$ são fortemente influenciados pelo teor de umidade de compactação. Pode-se verificar que os parâmetros obtidos por meio dos penetrômetros são capazes de descrever a condição de resistência em que o solo compactado na energia normal se encontra. Verifica-se que a relação da curva índice de penetração em função do teor de umidade, ajustada do tipo exponencial, apresenta-se com coeficiente de determinação $R^{2}=0,9444$, considerado um bom ajuste para os propósitos de engenharia.

Por fim, observa-se no presente trabalho que o índice de penetração determinado pelos penetrômetros de cone dinâmico permite a determinação de teor de umidade de compactação do solo (w), por tanto permite a determinação do desvio de teor de umidade de compactação $\left(\Delta \mathrm{w}=\mathrm{w}-\mathrm{W}_{\mathrm{ot}}\right)$. De posse também do teor de umidade ótimo, peso especifico aparente seco máximo e o índice de penetração (S), pode-se determinar o grau de compactação (CG). Para que isso seja possível há necessidade de determinar as curvas de calibração: índice de penetração em função do teor de umidade e grau de compactação em função do teor de umidade e índice de penetração, obtidas em laboratório com o solo compactado na energia de interesse.

\section{Agradecimentos}

Primeiramente a Deus por tudo que vem me proporcionando. Agradeço aos meus pais e amigos pelo apoio. Agradeço aos técnicos e professores da UEM, principalmente aos professores Jeselay Hemetério dos Reis e Antonio Belicanta, pelo apoio na pesquisa. Por fim agradece a Universidade Estadual de Maringá-UEM pelos recursos para a realização do trabalho.

\section{Referências}

[1] Belincanta, A.; Reis, J.; Michelan, P. P.; Estudo de correlação entre ensaios penetro métricos estáticos e dinâmicos. In: engenharia geotécnica para desenvolvimento, inovação e sustentabilidade. Maringá: 2010 UEM. 
FREITAS, J. H.; REIS, J. H.; BELINCANTA, A., ESTUDO DA INFLUÊNCIA DO TEOR DE UMIDADE NA VERIFICAÇÃO DO ÍNDICE DE PENETRAÇÃO ESTÁTICO E DINÂMICO. $2^{\circ}$ Simpósio Paranaense de Patologia das Construções ( ${ }^{\circ}$ SPPC), artigo 2SPPC2005, pp. 512-522, 2017. DOI: 10.4322/2SPPC.2017.042

[2] Crispim, F. A. Influência de variáveis de compactação na estrutura dos solos: caracterização geotécnica, química, mineralógica, e microestrutura. 2010. $125 f$. Dissertação (Doctor em Engenharia civil- Area de Geotecnia) - Universidade Federal de Viçosa, Viçosa, MG-Brasil. 2010.

[3] Stolf, R (1991): Teoria e teste experimental de fórmulas de transformação dos dados de penetrômetro de impacto em resistência do solo. Revista Brasileira de Ciência do Solo, Campinas, v.15, n.2.

[4] Alves, A. B. C; M.Sc; Triches, G. Metodologia de controle tecnológico de execução da camada final de terraplanagem utilizando o penetrômetro dinâmico de cone. GEOSUL 2002.

[5] Edil, T. B.; Benson, C. H. Investigation of soil stiffness gauge and dynamic cone penetrometer for earthwork property evaluation. Wisconsin: University of Wisconsin-Madson, 2004.

[6] Filho, H. B. M. Aplicação do cone de penetração dinâmica (CPD) como alternativa para fundações rasas. 2007. 128f. Dissertação (Mestrado em Engenharia civil- área Geotecnia) - Universidade Federal de Campina Grande, Campina Grande, PA-Brasil. 2004.

[7] Belincanta, A.; Reis, J.: Avaliação do uso de penetrômetro dinâmico de cone para controle de execução das fundações de pavimentos rodoviários. Maringá: UEM, 2004.

[8] Belincanta, A.; J.Lukiantchuki, A.; Reis, J. H. C. Control of soil compaction in pavement layers: A new approach using the dynamic cone penetrometer (DCP).State University of Maringa, Department of Civil Engineering. International Conference on Geotechnical and Geophysical site Characterisation, 2016, Gold Coast, 5th ISC, 2016, Australia.

[9] ABNT NBR 7182 (1984) SOLO- Ensaio de compactação. Associação Brasileira de Normas Técnicas- ABNT, São Paulo, Brasil.

[10] ABNT NBR 6457 (1986) AMOSTRA DE SOLO- Preparação para ensaios de caracterização". Associação Brasileira de Normas Técnicas- ABNT, São Paulo, Brasil.

[11] ABNT NBR 6508 (1984) Grãos de solos que passam na peneira de 4,8 mmDeterminação da massa especifica. Associação Brasileira de Normas TécnicasABNT, São Paulo, Brasil.

[12] ABNT NBR 7181 (1984) SOLO - Analise granulométrica. Associação Brasileira de Normas Técnicas- ABNT, São Paulo, Brasil. 